\title{
Radiation and Drought Impact Residual Leaf Conductance in Two Oak Species With Implications for Water Use Models
}

\author{
Haiyan Qin', Carles Arteaga2, Faqrul Islam Chowdhury33, Elena Granda4, Yinan Yao', \\ Ying Han ${ }^{1}$ and Víctor Resco de Dios $1,2,5 *$
}

' School of Life Sciences and Engineering, Southwest University of Science and Technology, Mianyang, China, ${ }^{2}$ Department of Crop and Forest Sciences, University of Lleida, Lleida, Spain, ${ }^{3}$ Institute of Forestry and Environmental Sciences, University of Chittagong, Chattogram, Bangladesh, ${ }^{4}$ Department of Life Sciences, University of Alcalá, Alcalá de Henares, Spain, ${ }^{5}$ Joint Research Unit CTFC-AGROTECNIO, Universitat de Lleida, Lleida, Spain

\section{OPEN ACCESS}

Edited by:

Attila Ördög,

University of Szeged, Hungary

Reviewed by:

Ismael Aranda,

National Institute for Agricultural and Food Research and Technology

(INIA), Spain

J.D. Lewis,

Fordham University, United States

Yasutomo Hoshika,

Institute for Sustainable Plant

Protection, Italian National Research

Council, Italy

${ }^{*}$ Correspondence:

Víctor Resco de Dios

v.rescodedios@gmail.com

Specialty section:

This article was submitted to

Plant Abiotic Stress,

a section of the journal

Frontiers in Plant Science

Received: 11 September 2020 Accepted: 10 November 2020

Published: 27 November 2020

Citation:

Qin H, Arteaga C, Chowdhury Fl,

Granda $E$, Yao Y, Han Y and

Resco de Dios V (2020) Radiation

and Drought Impact Residual Leaf

Conductance in Two Oak Species

With Implications for Water Use

Models. Front. Plant Sci. 11:603581.

doi: 10.3389/fp/s.2020.603581
Stomatal closure is one of the earliest responses to water stress but residual water losses may continue through the cuticle and incomplete stomatal closure. Residual conductance $\left(g_{\text {res }}\right.$ ) plays a large role in determining time to mortality but we currently do not understand how do drought and shade interact to alter gres because the underlying drivers are largely unknown. Furthermore, gres may play an important role in models of water use, but the exact form in which gres should be incorporated into modeling schemes is currently being discussed. Here we report the results of a study where two different oak species were experimentally subjected to highly contrasting levels of drought (resulting in 0,50 and $80 \%$ losses of hydraulic conductivity) and radiation (photosynthetic photon flux density at $1,500 \mu \mathrm{mol} \mathrm{m} \mathrm{m}^{-2} \mathrm{~s}^{-1}$ or $35-45 \mu \mathrm{mol}$ $\left.\mathrm{m}^{-2} \mathrm{~s}^{-1}\right)$. We observed that the effects of radiation and drought were interactive and species-specific and $g_{\text {res }}$ correlated positively with concentrations of leaf non-structural carbohydrates and negatively with leaf nitrogen. We observed that different forms of measuring $g_{r e s}$, based on either nocturnal conductance under high atmospheric water demand or on the water mass loss of detached leaves, exerted only a small influence on a model of stomatal conductance and also on a coupled leaf gas exchange model. Our results indicate that, while understanding the drivers of $g_{r e s}$ and the effects of different stressors may be important to better understand mortality, small differences in gres across treatments and measurements exert only a minor impact on stomatal models in two closely related species.

Keywords: cuticular conductance, stomatal conductance, night conductance, dark respiration, drought, shade

\section{INTRODUCTION}

Plant transpiration through stomatal pores and leaf cuticles dominates global evapotranspiration (Hetherington and Woodward, 2003). As water stress intensifies under global warming, there is an increasing interest toward understanding ecological variation in residual leaf conductance $\left(g_{\text {res }}\right)$. After stomatal closure, water loss continues until mortality due to a mixture of cuticular water loss 
and incomplete stomatal closure (residual conductance; Blackman et al., 2016; Martin-Stpaul et al., 2017).

Studies addressing ecological and physiological variation in the drivers of residual conductance are currently rare (Heredia-Guerrero et al., 2018). According to a recent review on this topic (Duursma et al., 2019), only 10 studies have addressed the effect of drought on $g_{\text {res }}$ and, from those, only 4 had been performed on trees. Consequently, multifactorial studies addressing ecological variation in residual conductance are much needed to understand its variation. For instance, while shade and drought are both known to decrease residual conductance (Boyer et al., 1997; Shepherd and Wynne Griffiths, 2006), it is currently unknown whether the effect of both stressors would be additive or interactive. However, the effects of residual conductance on mortality have been documented to be dramatic: time to mortality nearly doubles if $g_{\text {res }}$ declines from 4 to $2 \mathrm{mmol} \mathrm{m}^{-2} \mathrm{~s}^{-1}$ (Duursma et al., 2019).

Understanding the physiological and ecological drivers of $g_{\text {res }}$ has been the topic of some discussion (Riederer and Müller, 2007; Fernández et al., 2017). Some studies report that variations in the degree of sclerophylly (as indicated by leaf mass area) would increase $g_{\text {res }}$ because leaves that are more scleromorphic will show thicker cuticles, but other work has demonstrated that changes in wax composition may compensate for such effect (Bueno et al., 2020). Another alternative, explored to a lesser degree, is that further reductions in $g_{\text {res }}$ may be inhibited by changing carbohydrate allocation priorities (Zhang et al., 2020). In other words, as non-structural carbohydrate reserve pools deplete, cuticle production to prevent cuticular water losses may be limited by NSC availability.

Understanding variation in residual conductance is also necessary for models of water use (Leuning, 1995; Barnard and Bauerle, 2013; De Kauwe et al., 2015), where residual conductance acts as the intercept of commonly used stomatal models $\left(g_{\text {int }}\right)$. The most common stomatal models being used in land surface models are Ball-Berry model types, which have the general form:

$$
g_{\mathrm{s}}=g_{\text {int }}+m A / C_{\mathrm{a}} \mathrm{f}(\mathrm{D})
$$

Where $g_{s}$ is stomatal conductance, $A, C_{a}$, and $D$ represent photosynthesis, ambient $\mathrm{CO}_{2}$ concentration and vapor pressure deficit, respectively, and $m$ is the slope parameter. When $g_{\text {int }}$ is estimated through regression fitting, it may either be equal to 0 , which creates problems because then the ratio of intercellular to ambient $\mathrm{CO}_{2}\left(C_{i} / C_{a}\right)$ does not vary with light (Collatz et al., 1991; Leuning, 1995; Duursma et al., 2019), or it may be negative, which is nonsensical.

There are at least two possible definitions of $g_{\text {int }}$ : (1) $g_{0}$, which represents the lowest conductance reached as photosynthesis tends to 0 because light declines (Leuning, 1995; Barnard and Bauerle, 2013); (2) $g_{\min }$, which refers to the residual conductance after (complete or not) stomatal closure under strong water stress (Duursma et al., 2019). We note that some studies use $g_{\min }$ and $g_{\text {res }}$ interchangeably but, for clarity, we will differentiate them here as previously defined.
The problem then becomes how to measure $g_{0}$ and $g_{\min } \cdot g_{0}$ could simply be measured as daytime conductance $\left(g_{d}\right)$ under low light in non-droughted plants and, similarly, $g_{\min }$ could similarly be measured from $g_{d}$ in droughted plants (for as long as photosynthesis tends to zero, in both cases; Barnard and Bauerle, 2013; Duarte et al., 2016). Additionally, residual conductance has most often been measured by monitoring the water mass loss in detached leaves ( $g_{M L D}$; Kerstiens, 1996; Schuster et al., 2017). $g_{0}$ and $g_{\min }$ could thus be measured with this method by comparing $g_{M L D}$ in plants that have grown under strong light limitation or under strong water limitation, respectively. The problem with this approach, however, is that some acclimation responses (particularly in response to low radiation) could alter leaf morphology and it is unclear whether $g_{0}$ measured through $g_{M L D}$ after low light acclimation would be representative of that in plants without acclimation to low radiation.

An alternative would be to use nocturnal conductance $\left(g_{n}\right.$; Lombardozzi et al., 2017) in non-droughted and droughted plants. An advantage would be that photosynthesis would always be zero in this case. Duursma et al. (2019), however, proposed that $g_{n}$ should not be used given the evidence of active regulation of stomatal conductance overnight (Resco De Dios et al., 2019), and that the drivers of nocturnal conductance could differ from those driving daytime conductance (Ogle et al., 2012). Amongst other processes, $g_{n}$ varies through time due to circadian regulation (Resco De Dios et al., 2015). However, $g_{n}$ often retains some sensitivity to $D$ such that maximum stomatal closure and, potentially, residual conductance, may be achieved at lower $D$ than during the daytime (Barbour and Buckley, 2007). One could thus hypothesize that measurements of $g_{n}$ under high $D$ may be indicative of $g_{\text {res }}$.

Regardless of how $g_{0}$ and $g_{\min }$ are estimated, Duursma et al. (2019) proposed to replace Eq. 1 by:

$$
g_{\mathrm{s}}=\max \left[\max \left(g_{0}, g_{\min }\right), m A / C_{\mathrm{a}} \mathrm{f}(\mathrm{D})\right]
$$

That is, according to Eq. 2, residual conductance would not be added to the right-hand term of Eq. 1. Instead, one would use measured residual conductance (the maximum between $g_{0}$ and $g_{\text {min }}$ ) as an actual minimum (De Kauwe et al., 2015). However, this formulation has not yet been tested against data and, therefore, we do not yet know whether it enhances the predictive power of stomatal models.

Here we evaluate the effects of shade and water stress on $g_{\text {res }}$ across two different oak species, the deciduous Quercus faginea and the sclerophyll Q. ilex. These two species are common in the calcareous soils from Spain and the Western Mediterranean Basin and we expected conductance to be significantly lower in $Q$. ilex, a species with a more conservative water use. More specifically, we sought to test: (1) how do drought and shade interact to affect $g_{\text {res }}$ ? and (2) what are some of the possible mechanisms underlying variation in $g_{\text {res }}$ across drought and shade treatments? Because $g_{M L D}$ is probably the most accepted method to measure residual conductance, here we focused on $g_{M L D}$. In particular, we addressed whether $g_{M L D}$ would be driven by water stress (as indicated by water potential), NSC, LMA, or nitrogen concentration $\left(N_{\text {mass }}\right.$, an indicator of photosynthetic 
capacity), and whether $g_{\text {res }}$ could limit respiration. We also sought to understand: (3) whether we obtain different values of $g_{\text {res }}$ depending upon whether it is measured from $g_{M L D}, g_{n}$, and $g_{d}$; and (4) how do we incorporate residual conductance into BallBerry type stomatal models and what are the consequences of variation in $g_{\text {res }}$ across treatments and types of measurements for coupled leaf gas exchange models?

\section{MATERIALS AND METHODS}

\section{Experimental Design and Growing Conditions}

The experiment was performed at the experimental fields from the University of Lleida (Spain; $41.62 \mathrm{~N}, 0.59 \mathrm{E}$ ). We built a rain-out shelter covered by clear polyethylene plastic, which is commonly used in greenhouse building. Half of the structure received solar radiation (sun treatment), with a maximum photosynthetically active radiation (PAR) of $1,500 \mu \mathrm{mol} \mathrm{m} \mathrm{m}^{-2}$ $\mathrm{s}^{-1}$. The other half was covered by a dense shading cloth (shade treatment) with a maximum PAR of $35-45 \mu \mathrm{mol} \mathrm{m}^{-2} \mathrm{~s}^{-1}$, which was near the light compensation point in this species (data not shown). The structure had openings on both sides to increase ventilation. Temperature inside the rain out shelter was $3^{\circ} \mathrm{C}$ higher than outside, but differences between the sun and shade treatment were negligible. Full details on the infrastructure have been provided elsewhere (Resco De Dios et al., 2020).

For this study we sourced 2 year-old seedlings from local nurseries $(n=120)$. The ecotypes for both species were original from the mountain range of the Iberian System. Plants were grown in $11 \mathrm{~L}$ cubic pots $(20 \mathrm{~cm} \times 20 \mathrm{~cm} \times 27.5 \mathrm{~cm})$. The substrate used was Humin Substrat Neuhaus N6 [KlasmanDeilmann GmbH, Geeste, Germany], a commercial potting mix. Pots were regularly fertilized with a slow release NPK MgO fertilizer (17-09-11-2, Osmocote Universal, KB, Ecully, France) and daily watered to field capacity until treatment implementation. The position of the pots was randomly shifted every other week.

The plants grew for 4 months into the rainout shelter before experiment inception in July 2017. That is, they developed new leaves under the assigned experimental light conditions. Although we cannot discard legacy effects from the previous growing season in the nursery (Aranda et al., 2001), all plants were treated equally.

We performed a full factorial experiment with the plants experiencing two light treatments crossed with three water stress treatments. Half of the plants grew under the sun treatment and the other half under the shade treatment, as previously described. We implemented three different water stress treatments using three different levels of percent loss of hydraulic conductivity (PLC): (i) $\mathrm{P}_{0}$, where plants were irrigated at field capacity; (ii) $\mathrm{P}_{50}$, where plants experienced $50 \%$ losses in hydraulic conductivity and which represents an important stress; and (iii) $\mathrm{P}_{80}$, where the plant experienced $80 \%$ losses in hydraulic conductivity, which represents a major stress and potentially mortality (Resco et al., 2009).
We kept plants at field capacity until treatment implementation. We then stopped watering and allowed plants to dehydrate and we measured midday stem water potential $\left(\Psi_{m d}\right)$ every other day in a subset of plants $(n=5)$. The levels of PLC were controlled from the relation between midday shoot water potential $\left(\Psi_{m d}\right)$ and PLC values reported previously in vulnerability curves from Quercus faginea Lam. (Esteso-Martínez et al., 2006) and Quercus ilex L. (Peguero-Pina et al., 2014). Shoot $\Psi_{m d}$ was regularly measured during treatment implementation with a pressure bomb (PMS 1000, PMS Instruments, Albany, Oregon) after clipping the sample and allowing for equilibration in the dark for $\sim 30 \mathrm{~min}$. Once plants reached the target PLC, we kept soil moisture constant at that level for 2 weeks. This was achieved by weighing a subset of pots ( $n=5$ per each treatment) and adding back the water that had evaporated every day. We also measured native embolism to test the actual levels of PLC that we achieved in every treatment, as previously published (Resco De Dios et al., 2020). It is important to note that we did not always reach the target PLC levels (see Supplementary Table 1), but treatment implementation was successful in that we created a gradient in water availability with our treatments. Full details have been provided by Resco De Dios et al. (2020).

\section{Gas Exchange Measurements}

Leaf gas exchange was measured with a portable photosynthesis system (LI-6400XT, Li-Cor Inc., Lincoln, NE, United States). We measured 3-5 plants in each treatment at two different periods during the night: between 23:00 $\mathrm{h}$ and 01:00 $\mathrm{h}$ and between 03:00 $\mathrm{h}$ and 05:00 $\mathrm{h}$, and also during the day (10:00-13:00 h). We did not observe significant differences between the stomatal conductance measured over night at the different times $(p=0.79)$ and measurements were pooled together in subsequent analyses. To understand if measurement errors arising from low flux rates affected our measurements, we also conducted measurements with an empty chamber for 4-5 h, following previously published protocols (Resco De Dios et al., 2013). Results were always one or more orders of magnitude lower or negative. Given these results, we concluded that leaf observations were reliable and that a general correction was not required.

Block temperature was set at $25^{\circ} \mathrm{C}$ during the night and at $30^{\circ} \mathrm{C}$ during the day, $\mathrm{CO}_{2}$ at $400 \mathrm{ppm}$ and relative humidity at $\sim 30 \%$. This meant that $D$ during nighttime measurements was at $\sim 2.2 \mathrm{kPa}$, which was substantially higher than that naturally occurring during the night (Resco De Dios et al., 2020). We chose this design to induce nocturnal stomatal closure and test whether $g_{n}$ indicates $g_{\text {res }}$.

During the daytime, we performed measurements at two different levels of PAR: $1,500 \mu \mathrm{mol} \mathrm{m}{ }^{-2} \mathrm{~s}^{-1}$ and $40 \mu \mathrm{mol} \mathrm{m}^{-2}$ $\mathrm{s}^{-1}$. We first measured under growth PAR $\left(1,500 \mu \mathrm{mol} \mathrm{m}{ }^{-2}\right.$ $\mathrm{s}^{-1}$ for plants in the sun treatment and $40 \mu \mathrm{mol} \mathrm{m} \mathrm{m}^{-2} \mathrm{~s}^{-1}$ for plants in the shadow treatment) and then at the other PAR level $\left(40 \mu \mathrm{mol} \mathrm{m}^{-2} \mathrm{~s}^{-1}\right.$ for plants in the sun treatment and 1,500 $\mu \mathrm{mol}$ $\mathrm{m}^{-2} \mathrm{~s}^{-1}$ for plants in the shadow treatment). The leaves were exposed for 10-20 min under the different light intensities until acclimation to the new light level. We only used data measured under growth PAR for analyses, and the rest was reserved for model validation. We note that a sudden exposure to $1,500 \mu \mathrm{mol}$ 
$\mathrm{m}^{-2} \mathrm{~s}^{-1}$ for a plant growing in the shade would represent a sunfleck, and this could affect the performance of steady-state stomatal models (Way and Pearcy, 2012). When the leaf did not cover the chamber completely, it was scanned and we corrected measurements for leaf area.

In order to parameterize the photosynthesis component of the coupled leaf gas exchange model, we also measured the response of photosynthesis $(A)$ to different internal $\mathrm{CO}_{2}$ concentrations $\left(C_{i}\right)$ following the protocols from Long and Bernacchi (2003). Briefly, we started measurements with an ambient $\mathrm{CO}_{2}$ concentration $\left(C_{a}\right)$ of $400 \mathrm{ppm}$ and, after $5 \mathrm{~min}$ of acclimation, we sequentially changed $C_{a}$ to $300,250,200,150$, $100,50,0,400,500,650,800,1000,1250$, and $1500 \mathrm{ppm}$. These measurements were performed at saturating light $(1,500 \mu \mathrm{mol}$ $\mathrm{m}^{-2} \mathrm{~s}^{-1}$ ), setting block temperature at $30^{\circ} \mathrm{C}$ and with $\mathrm{RH}$ as high as we could achieve, which was $\sim 50 \%$.

\section{Measurements of $\boldsymbol{g}_{M L D}$}

$g_{M L D}$ was measured as the mass loss of detached leaves following Phillips et al. (2010) in five leaves per treatment, weighting the leaves every $5 \mathrm{~min}$ during $2 \mathrm{~h}$ after collection. We wrapped the petiole with paraffilm so that only water lost through the leaf was measured. We performed the measurements in the laboratory, briefly after collection, where we monitored the temperature and relative humidity. Residual conductance was then calculated as:

$$
g_{\mathrm{MLD}}=E_{\mathrm{MLD}} P D^{-1}
$$

where $E_{M L D}$ is mass loss per projected leaf area $\left(\mathrm{mol} \mathrm{m}^{-2} \mathrm{~s}^{-1}\right), P$ is atmospheric pressure $(\mathrm{kPa})$ and $D$ is the vapor pressure deficit $(\mathrm{kPa}) . g_{0}$ was defined as $g_{M L D}$ when the leaf originated from the shade treatment at $P_{0}\left(P_{0} \_\right.$shade $)$and $g_{\min }$ was defined as $g_{M L D}$

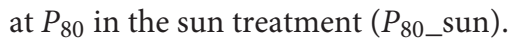

\section{Analyses of Non-structural Carbohydrates and Elemental Composition}

To better understand the physiological mechanisms explaining variations in $g_{\text {res }}$ with treatments, we analyzed the concentrations of non-structural carbohydrates, changes in leaf mass per area (LMA) and nitrogen concentrations $\left(N_{\text {mass }}\right)$. We collected all the leaves in five plants for each treatment. Immediately after collection, we scanned the leaves to measure the total area and they were then microwaved for $30 \mathrm{~s}$ and $700 \mathrm{~W}$ to stop further metabolic processes. We then oven dried the samples (48 $\mathrm{h}$ in $105^{\circ} \mathrm{C}$ ) and recorded the dry mass. Leaf area and dry weight was used to estimate LMA.

We followed previously developed protocols for extracting the percentage for sugar and starch (Palacio et al., 2007). This method consists of grinding the dried leaves with a mill (IKA A10, IKA-Werke, Staufen, Denmark) and making two extractions: one for extracting soluble sugars (sugars from now on) and a second extraction for starch. The first step of the sugar extraction consisted of adding $10 \mathrm{ml}$ of ethanol $(80 \% \mathrm{v} / \mathrm{v})$ to $50 \mathrm{mg}$ of sample, which we then left for $30 \mathrm{~min}$ at $60^{\circ} \mathrm{C}$ in water bath, and then we centrifuged (NEYA 8, REMI ELEKTROTECHNIK LTD., Vasai, India) the sample for $10 \mathrm{~min}$ at $3200 \mathrm{rpm}$. In the second step we added $50 \mu \mathrm{l}$ of the supernatant, $450 \mu \mathrm{l}$ of ethanol (80\%), $500 \mu \mathrm{l}$ of phenol (28\%), and $2500 \mu \mathrm{l}$ of sulfuric acid (96\%), we shook the mix and let it stand for $30 \mathrm{~min}$. In the third step we read the absorbance at $490 \mathrm{~nm}$ with spectrophotometer (Spectrophotometer UV-1600PC, VWR, Radnor, PA, United States) after removing the supernatant and drying the sample at $70^{\circ} \mathrm{C}$ during $16 \mathrm{~h}$.

In the starch extraction, we added $4 \mathrm{ml}$ of sodium acetate $(\mathrm{pH} 4.5)$ to the dry sample and left it for $60 \mathrm{~min}$ in a water bath $\left(60^{\circ} \mathrm{C}\right)$. Once the sample cooled down, we added $1 \mathrm{ml}$ of Amyloglucosidase $(0.5 \% \mathrm{w} / \mathrm{v})$ and we incubated the mix in the stove for $16 \mathrm{~h}$ at $50^{\circ} \mathrm{C}$. We then added sample $50 \mu \mathrm{l}$ of supernatant, $450 \mu \mathrm{l}$ of sodium acetate $(\mathrm{pH} 4.5), 500 \mu \mathrm{l}$ of phenol (28\%), and 2,500 $\mu \mathrm{l}$ of sulfuric acid (96\%). We then mixed it and let sit for $30 \mathrm{~min}$, and then we measured the absorbance at $490 \mathrm{~nm}$ with the spectrophotometer.

We analyzed nitrogen concentration in an elemental analyzer (Carlo Erba 1110 Elemental Analyzer) at the University of Wyoming following previously published procedures (Hoffman et al., 2019).

\section{Statistical Analyses}

We examined statistical differences across treatments in $g_{M L D}$, $g_{n}$, and $g_{d}$ using an ANOVA (followed by Tukey's HSD test) with species, light and water treatments as explanatory variables. Measurements of $g_{M L D}$, were conducted on different individuals within a treatment. Consequently, we examined whether values were comparable within a given treatment by examining variation in the mean $\pm 95 \% \mathrm{CI}$ in $g_{M L D}, g_{n}$, and $g_{d}$.

To examine potential drivers of variation in $g_{\text {res }}$, we additionally performed correlation analyses between conductance and NSC, LMA, gas exchange parameters and $\Psi_{\text {md }}$.

All data was analyzed with R 3.6.3 (R Core Team, 2020) using base packages and, additionally, "corrplot" for plotting the correlation table (Wei and Simko, 2017).

\section{Modeling}

In order to examine the effects of the different forms of measuring residual conductance over stomatal predictions and coupled photosynthetic responses, we performed two exercises. First, we examined the effects on stomatal predictions on different implementations of Eqs 1, 2. Second, we examined the effects of the different measured values of $g_{\text {res }}$ on a photosynthesis-stomatal conductance coupled model.

For the first exercise, we compared the performance of different versions of the Ball-Berry (BB) model (Ball et al., 1987). First, we examined the version proposed by Duursma et al. (2019, BBD):

$$
g_{\mathrm{s}}=\max \left[\max \left(g_{0}, g_{\min }\right), m \mathrm{ARH} / C_{\mathrm{a}}\right]
$$

and we used three different forms of the left hand term [ $\max \left(g_{0}\right.$, $\left.g_{\text {min }}\right)$ ]. That is, we compared model performance when the left hand term used $g_{0}$ and $g_{\text {min }}$ estimated from $g_{M L D}\left(\mathrm{BBD}_{M L D}\right)$, $g_{n}\left(\mathrm{BBD}_{n}\right)$, and $g_{d}\left(\mathrm{BBD}_{d}\right)$. In all cases, $g_{0}$ was defined as conductance $\left(g_{M L D}, g_{n}\right.$, or $g_{d}$, depending on the case) in the 
shade treatment without water stress $\left(P_{0 \_}\right.$shade) and $g_{\min }$ as conductance in the sun under strong water stress $\left(P_{80 \_}\right.$sun).

We compared these results with the original version of the Ball-Berry model (BB):

$$
g_{\mathrm{s}}=g_{\text {int }}+m \mathrm{ARH} / C_{\mathrm{a}}
$$

where $g_{\text {int }}$ and $m$ were both estimated through least squares fitting.

Finally, we used an intermediate option where we used Eq. 5 but where $g_{\text {int }}$ was replaced by actual $g_{M L D}$ measurements (BB_meas_g ${ }_{M L D}$ ), instead of being estimated through least squares. We also tried with $g_{n}$, in addition to $g_{M L D}$, but differences were negligible, as will be discussed later in more detail.

Model calibration was performed with data collected under growth PAR $\left(1,500 \mu \mathrm{mol} \mathrm{m} \mathrm{m}^{-2} \mathrm{~s}^{-1}\right.$ for sun treatment and $40 \mu \mathrm{mol} \mathrm{m} \mathrm{m}^{-2} \mathrm{~s}^{-1}$ for the shade treatment). Model validation was performed with data collected under different PAR levels. That is, with PAR at $40 \mu \mathrm{mol} \mathrm{m} \mathrm{m}^{-2} \mathrm{~s}^{-1}$ for the sun treatment and at $1,500 \mu \mathrm{mol} \mathrm{m} \mathrm{m}^{-2} \mathrm{~s}^{-1}$ for the shade treatment. Model comparison was performed calculating the Akaike Information Criterion (AIC) and a model was considered more plausible when the AIC was smaller by a difference of 2 or more units (Burnham and Anderson, 2002). We also examined the variation in the slope, intercept and $\mathrm{R}^{2}$ of the observed $v s$ predicted relationship.

For the second exercise, we simulated the effects of the different values of $g_{M L D}, g_{n}$ and $g_{d}$ on predictions of $C_{i}$ with varying PAR and on the effect temperature on leaf evaporation. We used the $A / C_{i}$ curves to parameterize a coupled photosynthesis model (Duursma, 2015) and we conducted the simulation following previously published protocols (Duursma et al., 2019). We note that differences in mesophyll conductance across species and treatments could affect estimates of photosynthetic parameters (Flexas et al., 2012).

\section{RESULTS}

\section{Effects of Shade and Drought on $g_{M L D}$ and $g_{n}$}

We observed that $g_{M L D}$ varied significantly with species and light and also with light and water (Table $\mathbf{1}$ and Figure 1). The interactions between species and light resulted in $g_{M L D}$ significantly declining from 6.9 in the sun to $3.4 \mathrm{mmol} \mathrm{m}^{-2} \mathrm{~s}^{-1}$ shadow in Q. faginea. However, $g_{M L D}$ in Q. ilex did not differ across light levels (5.6 in the sun and $4.4 \mathrm{mmol} \mathrm{m}^{-2} \mathrm{~s}^{-1}$ in the shade). The interaction between light and water was such that $g_{M L D}$ declined with drought in the sun treatment (from 7.4 at $\mathrm{P}_{0}$ to $5.5 \mathrm{mmol} \mathrm{m}^{-2} \mathrm{~s}^{-1}$ at $\mathrm{P}_{80}$ ), but $g_{M L D}$ increased with drought in the shade from 3.1 at $\mathrm{P}_{50}$ to $5.0 \mathrm{mmol} \mathrm{m}^{-2} \mathrm{~s}^{-1}$ at $\mathrm{P}_{80}$ ).

Variation in $g_{n}$ followed a pattern of variation similar to that of $g_{M L D}$ in that it also varied significantly with species and light treatments (Table 1 and Figure 2). $g_{n}$ was not different between species at the shade treatment $\left(4.5\right.$ and $5.6 \mathrm{mmol} \mathrm{m}^{-2} \mathrm{~s}^{-1}$ in $Q$. faginea and $Q$. ilex, respectively), but there was a significant increase in $g_{n}$ in Q. faginea $\left(7.8 \mathrm{mmol} \mathrm{m}^{-2} \mathrm{~s}^{-1}\right)$ in the sun
TABLE 1 | ANOVA Table on the effects of species, light treatment, water treatment on residual conductance measured from the mass loss of detached leaves ( $\left.g_{M L D}\right)$, from nocturnal conductance $\left(g_{n}\right)$, and also from daytime conductance $\left(g_{d}\right)$.

\begin{tabular}{|c|c|c|c|}
\hline Factor & Df & $\boldsymbol{F}$ & $P$-value \\
\hline \multicolumn{4}{|l|}{$g_{M L D}$} \\
\hline Species & 1 & 0.12 & 0.73 \\
\hline Light & 1 & 23.4 & $<0.0001$ \\
\hline Water & 2 & 1.35 & 0.27 \\
\hline Species $\times$ Light & 1 & 5.41 & 0.02 \\
\hline Species $\times$ Water & 2 & 0.75 & 0.48 \\
\hline Light $\times$ Water & 2 & 4.04 & 0.02 \\
\hline Species $\times$ Light $\times$ Water & 2 & 0.35 & 0.71 \\
\hline \multicolumn{4}{|l|}{$g_{n}$} \\
\hline Species & 1 & 0.89 & 0.35 \\
\hline Light & 1 & 1.27 & 0.26 \\
\hline Water & 2 & 2.14 & 0.12 \\
\hline Species $\times$ Light & 1 & 4.98 & 0.03 \\
\hline Species $\times$ Water & 2 & 2.53 & 0.09 \\
\hline Light $\times$ Water & 2 & 0.14 & 0.87 \\
\hline Species $\times$ Light $\times$ Water & 2 & 0.20 & 0.82 \\
\hline \multicolumn{4}{|l|}{$g_{d}$} \\
\hline Species & 1 & 5.84 & 0.02 \\
\hline Light & 1 & 51.21 & $<0.001$ \\
\hline Water & 2 & 138.66 & $<0.001$ \\
\hline Species $\times$ Light & 1 & 16.99 & $<0.001$ \\
\hline Species $\times$ Water & 2 & 1.08 & 0.34 \\
\hline Light $\times$ Water & 2 & 91.74 & $<0.001$ \\
\hline Species $\times$ Light $\times$ Water & 2 & 21.24 & $<0.001$ \\
\hline
\end{tabular}

treatment. Instead, $g_{n}$ in $Q$. ilex at the sun treatment was similar to that in the shade $\left(4.0 \mathrm{mmol} \mathrm{m}^{-2} \mathrm{~s}^{-1}\right.$; Figure 1B). Differences across water treatments were not significant.

\section{Effects of Shade and Drought on $\boldsymbol{g}_{\boldsymbol{d}}$}

Of particular relevance for this study is to examine $g_{d}$ when $A_{n e t}$ approaches zero (Figure $3 B$ ), so that one can test the potential use of $g_{d}$ as an indicator of residual conductance. There are different definitions in the literature as to what is meant by photosynthesis approaching zero (Leuning, 1995; Barnard and Bauerle, 2013). Here we used $g_{d}$ when $A_{n e t}$ was at, or below, $1 \mu \mathrm{mol} \mathrm{m}^{-2} \mathrm{~s}^{-1}$. In Q. faginea, this occurred under the shade treatments at all water stress levels, where $g_{d}$ varied between 14.6 and $29.5 \mathrm{mmol} \mathrm{m}^{-2}$ $\mathrm{s}^{-1}$ (Figure 3).

In Q. ilex, $A_{\text {net }}$ was always below $1 \mu \mathrm{mol} \mathrm{m} \mathrm{m}^{-2} \mathrm{~s}^{-1}$ in the shadow treatments at all water stress levels. However, there was significant variation in $g_{d}$ as it varied from $58 \mathrm{mmol} \mathrm{m}^{-2} \mathrm{~s}^{-1}$ in $\mathrm{P}_{0}$ to 14 and $4 \mathrm{mmol} \mathrm{m}^{-2} \mathrm{~s}^{-1}$ in $\mathrm{P}_{50}$ and $\mathrm{P}_{80}$, respectively. Within the sun treatments, $A_{n e t}$ was always below 1 under water stress (at $\mathrm{P}_{50}$ and $\mathrm{P}_{80}$ ) where $g_{d}$ varied between 4 and $1 \mathrm{mmol} \mathrm{m}^{-2} \mathrm{~s}^{-1}$, respectively. $g_{d}$ under water stress $\left(\mathrm{P}_{50}\right.$ and $\left.\mathrm{P}_{80}\right)$ was not different between shadow and sun treatments (Figures 3A,B).

\section{Differences Between $g_{M L D}, g_{n}$, and $g_{d}$}

Within a given treatment, $g_{n}$ was indistinguishable from $g_{M L D}$ : 95\% CI error bars always overlapped (Figure 3C). In Q. faginea, 

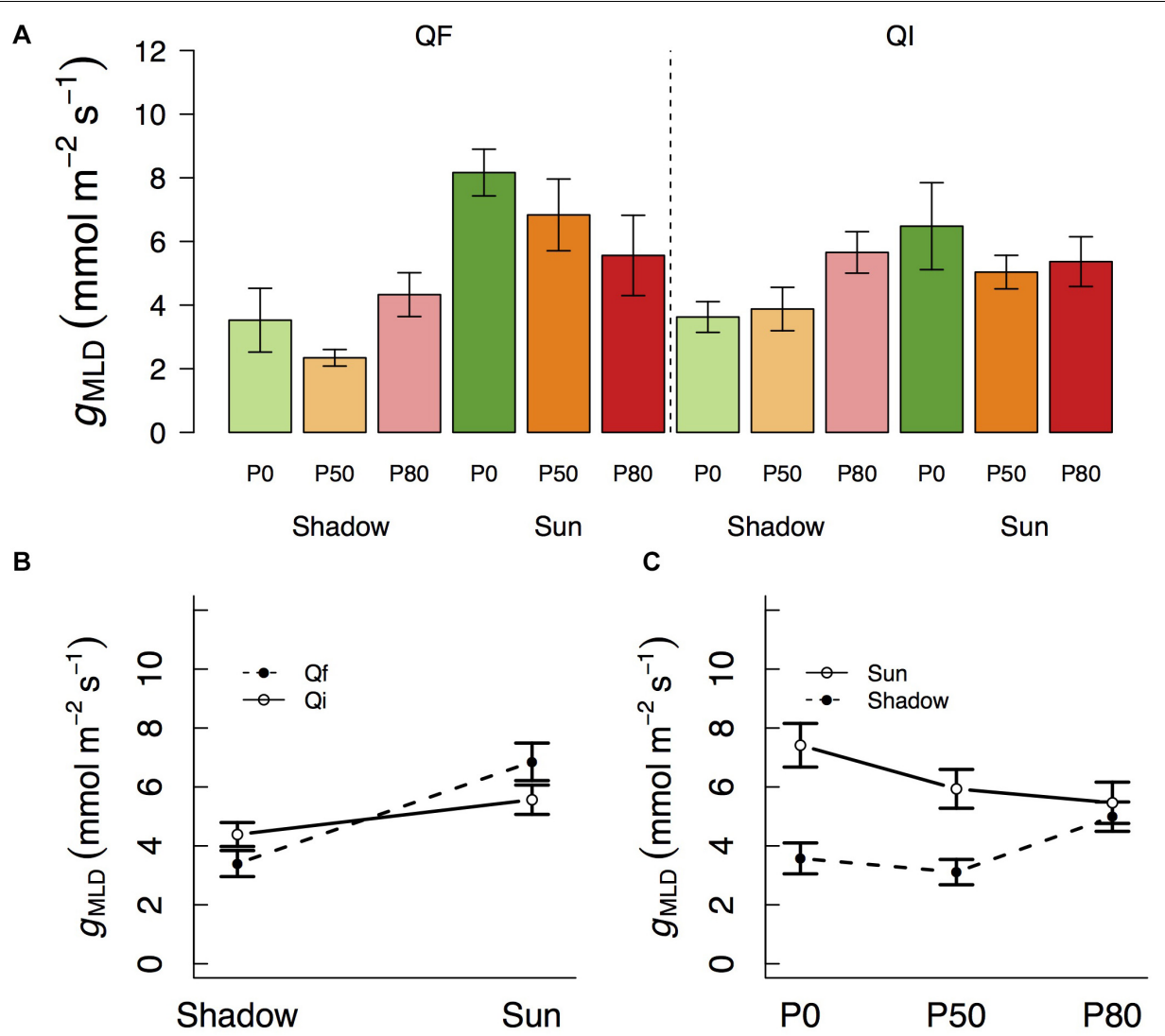

FIGURE 1 | (A) Variation in residual conductance measured from the mass loss of detached leaves ( $g_{M L D}$ ) across different light treatments (shadow vs sun) and water treatments $\left(\mathrm{P}_{0}, \mathrm{P}_{50}\right.$, and $\left.\mathrm{P}_{80}\right)$. Significant interactions across treatments are plotted in $\mathbf{( B , C )}$. Bars indicate mean values per treatment and error bars indicate SE.

values of $g_{M L D}$ were usually below those of $g_{n}$, but the absolute difference was less than $4 \mathrm{mmol} \mathrm{m}^{-2} \mathrm{~s}^{-1}$. In Q. ilex, the difference between $g_{n}$ and $g_{M L D}$ was less than $1 \mathrm{mmol} \mathrm{m}^{-2} \mathrm{~s}^{-1}$.

In contrast, $g_{d}$ was consistently and significantly above both, $g_{M L D}$ and $g_{n}$ in $Q$. faginea. It should be noted that, for this comparison, we only used $g_{d}$ when $A_{n e t}$ was below $1 \mu \mathrm{mol} \mathrm{m}{ }^{-2}$ $\mathrm{s}^{-1}$. That is, we did not seek to compare values of $g_{d}$ with $g_{M L D}$ and $g_{n}$ if $A_{n e t}$ was above $1 \mu \mathrm{mol} \mathrm{m}{ }^{-2} \mathrm{~s}^{-1}$ because, in that case, photosynthesis does not tend to zero. The average difference of $g_{d}$ with $g_{M L D}$ was $17.7 \mathrm{mmol} \mathrm{m}^{-2} \mathrm{~s}^{-1}$ and the average difference of $g_{d}$ with $g_{n}$ was $10 \mathrm{mmol} \mathrm{m}^{-2} \mathrm{~s}^{-1}$. The only case in which $g_{d}$ was not different from $g_{M L D}$ and $g_{n}$ was in the sun treatments in $Q$. ilex.

\section{Correlates Explaining Variation in $\mathbf{g}_{\mathbf{M L D}}$}

Overall, the relationships between the different indicators of $g_{M L D}$ and other physiological parameters were species-specific (Figure 4A). The only exceptions were $N_{\text {mass }}$ and NSC concentrations which had a negative and a positive correlation, respectively, with $g_{M L D}$ in both species (Figure 4). In turn, $N_{\text {mass }}$ correlated negatively with NSC concentrations and LMA in both species. NSC also correlated with LMA in both species, albeit positively. In Q. faginea, $g_{M L D}$ and $g_{n}$ also correlated positively with LMA and $g_{M L D}$ also correlated positively. In
Q. ilex, $g_{n}$ showed a negative correlation with respiration $(R)$ and a positive correlation with $\Psi_{m d}$ and with $A_{\text {net. NSC }}$ concentrations were negatively affected by the shade treatment (Supplementary Figure 1A).

\section{Modeling $g_{d}$ : Comparing Different Formulations of the BB Model}

We first compared the performance of the model proposed by Duursma et al. (2019) when $g_{0}$ and $g_{\text {min }}$ had been defined on the basis of $g_{M L D}\left(\mathrm{BBD}_{M L D}\right)$, of $g_{n}\left(\mathrm{BBD}_{n}\right)$, and of $\mathrm{g}_{d}\left(\mathrm{BBD}_{d}\right)$. In all cases, the original $g_{0}$ and $g_{\text {min }}$ were defined as the level conductance $\left(g_{M L D}, g_{n}\right.$, or $g_{d}$, depending on case) in the $\mathrm{P}_{0 \_}$shade treatment (low light) and in the $\mathrm{P}_{80}$ sun treatment, respectively, (high water stress).

Model performance was superior when the model was based on $g_{M L D}\left(\mathrm{BBD}_{M L D}\right)$, but differences with the model based on $g_{n}$ were minor $(\triangle \mathrm{AIC}=0.3$ for $Q$. faginea and 2.3 for $Q$. ilex $)$. However, the model based on $g_{d}$ showed consistently a larger AIC, indicating smaller plausibility (Table 2).

We compared the performance of these three models against the original Ball- Berry (BB) and we observed that $\mathrm{BBD}_{M L D}$ and $\mathrm{BBD}_{n}$ performed better only in $Q$. faginea, where the difference in AIC was bigger than 4. For Q. ilex, however, the AIC was similar across models although the intercept of the observed 


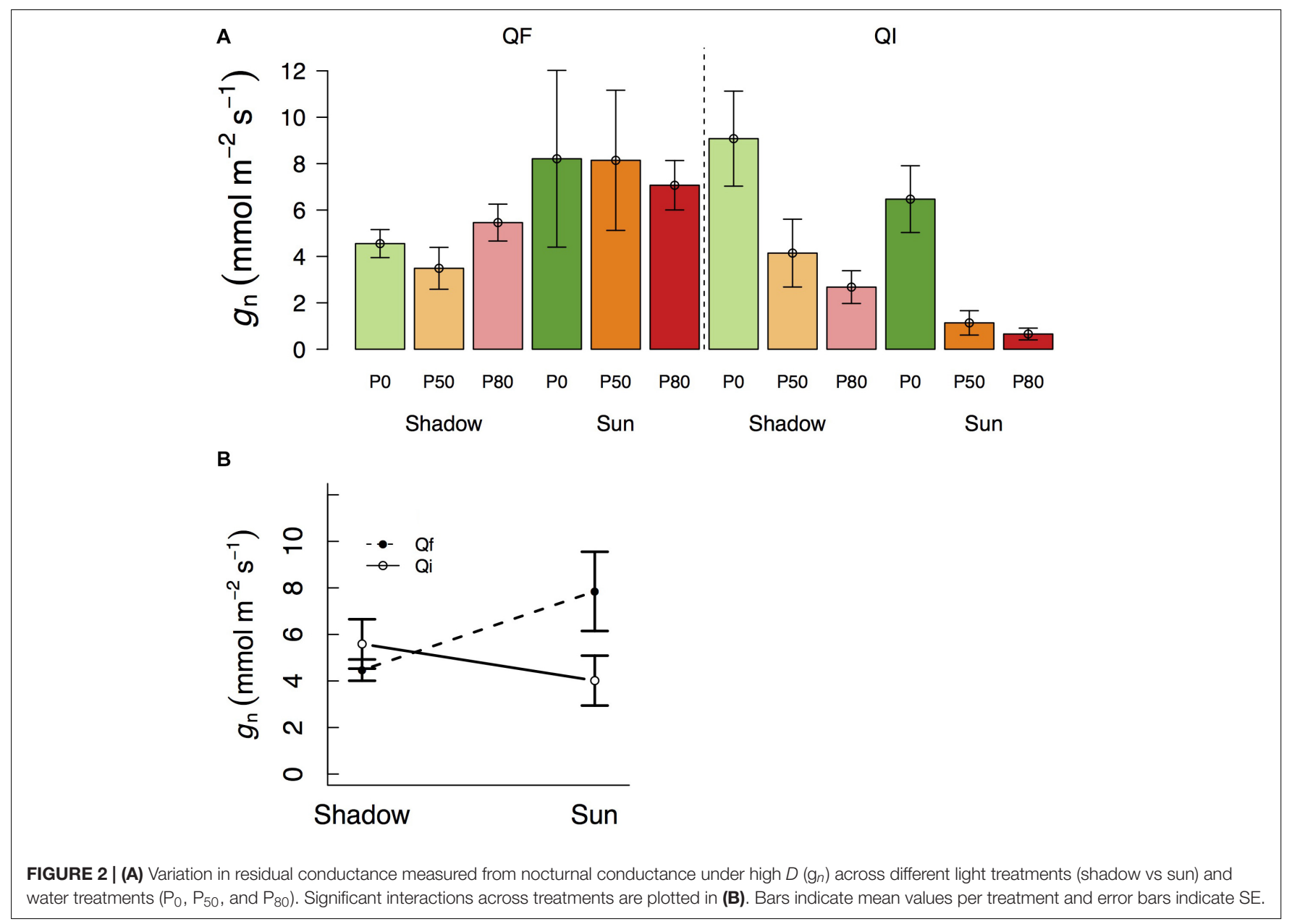

$v s$ predicted relationship was significantly different from 0 only in the BB model.

Finally, we compared the performance of the Ball-Berry model but where, instead of fitting $g_{\text {int }}$ through least squares, we use actual $g_{M L D}$ measurements (BB_meas_ $g_{M L D}$ ), which we defined originally as $g_{M L D}$ under water stress $\left(\mathrm{P}_{80} \_\right.$sun $)$. We observed that this was the best model in $Q$. ilex as it had the smallest AIC although the difference was not significant with $\mathrm{BBD}_{M L D}$ $(\triangle \mathrm{AIC}=1.64)$. In $\mathrm{Q}$. faginea, BB_meas_ $g_{M L D}$ peformed worst than $\mathrm{BBD}_{M L D}(\triangle \mathrm{AIC}=2.6)$.

Differences between BB_meas_g $g_{M L D}$ were significant with the $\mathrm{BB}$ model ( $\mathrm{AIC}=2$ for both species) and it was also more plausible than the $\mathrm{BBD}_{d}$ model in $\mathrm{Q}$. faginea $(\mathrm{AIC}>2$ ). Differences between BB_meas_gint and the other models were not significant. We tried fitting BB_meas_ $g_{\text {int }}$ with different values of $g_{\text {int }}$ (e.g., using values under shade, or from $g_{n}$ ), but differences were not significant (data not shown).

\section{Modeling $g_{d}$ : Coupled Leaf Gas Exchange Model}

Depending on how $g_{\text {res }}$ was measured, we found significant differences of simulated gas exchange. In particular, when $g_{d}$ was used we always observed higher values of $C_{i}$ at any PAR level and also higher leaf transpiration rates $\left(E_{l}\right)$ as temperatures increased because $g_{d}$ was often larger than $g_{M L D}$ and $g_{n}$ (Figure 5).

Generally speaking, there was little difference in simulated $C_{i}$ and $E_{l}$ regardless of whether $g_{M L D}$ or $g_{n}$ were used, and whether they were defined from $g_{0}$ or from $g_{\min }$. The only exception was that, in $Q$. ilex, there were some differences in predicted $C_{i}$ (particularly at low PAR levels) and in predicted leaf transpiration (particularly at peak $E_{l}$ ) when $g_{\text {res }}$ was defined from $g_{n}$ : using $g_{n}$ from the $\mathrm{P}_{0 \_}$shade $\left(g_{0}\right)$ treatment led to higher predicted $C_{i}$ and $E_{l}$ than using $g_{n}$ from the $\mathrm{P}_{80} \_$sun treatment $\left(g_{\text {min }}\right)$. It should be noticed that $g_{n}$ from the $\mathrm{P}_{0} \_$shade treatment was one order of magnitude larger than $g_{n}$ from the $\mathrm{P}_{80}$ sun treatment (9.1 vs $0.6 \mathrm{mmol} \mathrm{m}^{-2} \mathrm{~s}^{-1}$, respectively).

\section{DISCUSSION}

We observed that residual conductance varied significantly across light and water treatments in an interactive (nonadditive) fashion and the responses differed across species. There were no significant differences as to whether residual conductance was measured from $g_{M L D}$ or from $g_{n}$, but the values were significantly higher when using $g_{d} \cdot g_{M L D}$ was positively correlated with NSC concentrations, suggesting that further 

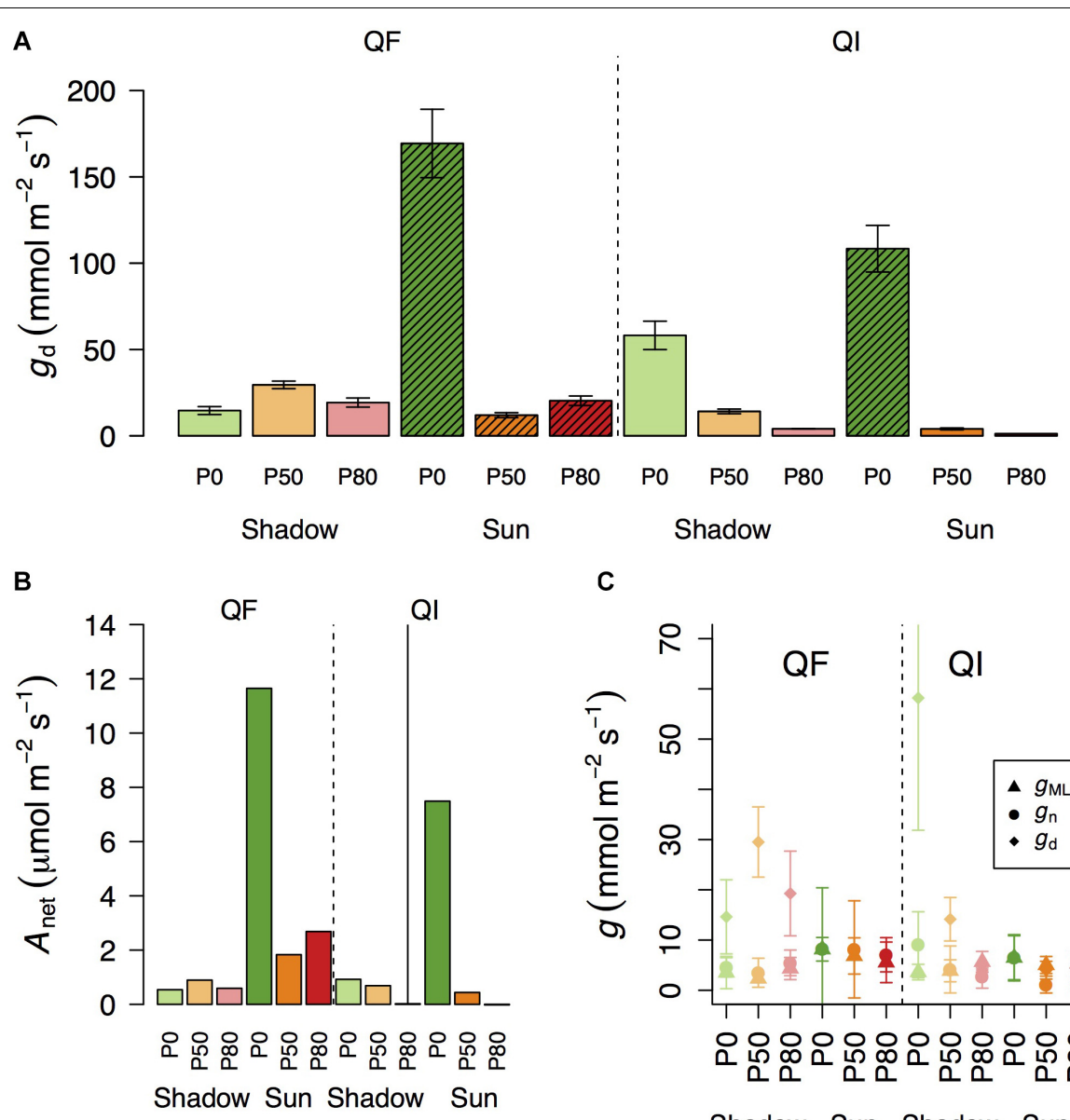

C

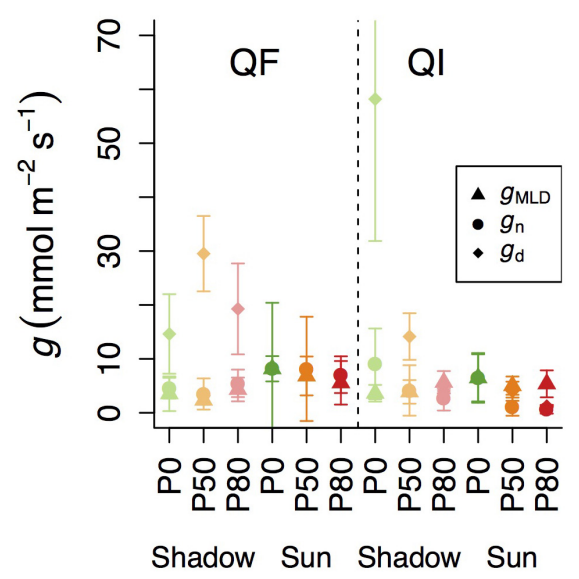

FIGURE 3 | Variation in daytime leaf conductance $\left(\mathbf{A}, g_{d}\right)$ and net assimilation $\left(\mathbf{B}, A_{\text {net }}\right)$ across different light treatments (shadow vs sun) and water treatments $\left(\mathrm{P}_{0}\right.$, $\mathrm{P}_{50}$, and $\left.\mathrm{P}_{80}\right)$. Bars indicate mean values per treatment and error bars indicate SE. Hatched bars in (A) indicate that $A_{\text {net }}$ in that treatment is significantly higher than 1. (C) Differences in residual conductance as measured by from the mass loss of detached leaves ( $\left.g_{M L D}\right)$, from nocturnal conductance under high $D$ ( $\left.g_{n}\right)$, or from $g_{d}$ when $A_{\text {net }}$ was smaller than 1 [note that some values of $g_{d}$ are missing in $\mathbf{( C )}$ if $A_{\text {net }}$ for that treatment was higher than 1]. Error bars indicate $95 \%$ Cl.

reductions in $g_{M L D}$ under drought may be limited by low NSC availability. From a modeling perspective, the small measured differences between $g_{M L D}$ and $g_{n}$ generally did not impact model performance. Although residual conductance differed significantly under experimental treatment, such differences in residual conductance showed only a moderate impact on model performance. That is, model performance did not critically depend upon whether residual conductance was measured under strong shade or under strong water stress. There was also little difference in model fit when either $g_{M L D}$ or $\mathrm{g}_{n}$ were used as an absolute minimum in Eq. $4\left(\mathrm{BBD}_{M L D}\right.$ or $\left.\mathrm{BBD}_{n}\right)$, or when they were used as the intercept of the $\mathrm{BB}$ equation (BB_meas_g $g_{M L D}$ ).

\section{Shade and Drought Interact as Drivers of g $_{\text {MLD }}$ Although Responses Are Species-Specific}

We observed that $g_{M L D}$ declined under increasing drought in the sun treatment. In the shade treatment, however, $g_{M L D}$ remained low and constant, regardless of the water treatment. This result indicates that drought only affects $g_{M L D}$ under high light because, under shade, light limitations lower $g_{M L D}$ to a minimum that is not affected by water stress. It is worth noting that, at least for some species, full acclimation after changes in the light growth environment may require more than one growing season (Aranda et al., 2001). In other words, the strong limitation imposed by the low light over $g_{M L D}$ may increase even more in subsequent years.

Previous studies had identified how $g_{M L D}$ often decreases under exposure to water stress and light, as a result of changes in wax composition, when each effect is examined in isolation (Shepherd and Wynne Griffiths, 2006). However, our experiment may be the first to examine $g_{M L D}$ responses in a multifactorial experiment. Interestingly, light and water effects were not additive. That is, we did not observe a lower $g_{M L D}$ under low light and high water stress, as would be expected from an additive effect of both factors.

The response to shade was, however, species-specific. $g_{M L D}$ increased in the sun treatment only in the deciduous 
A

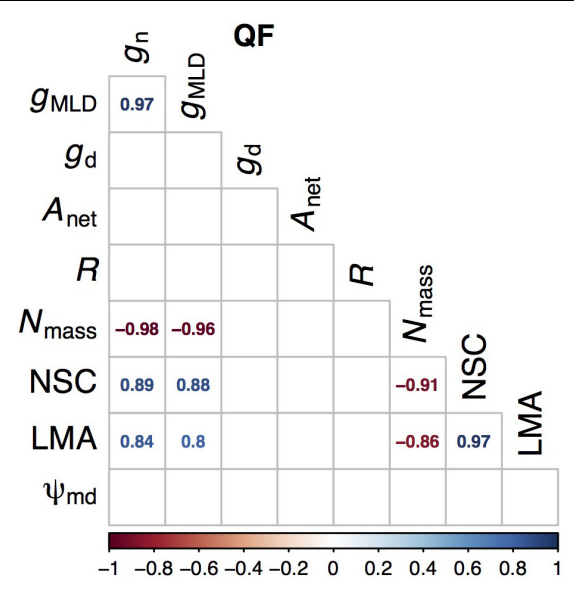

C

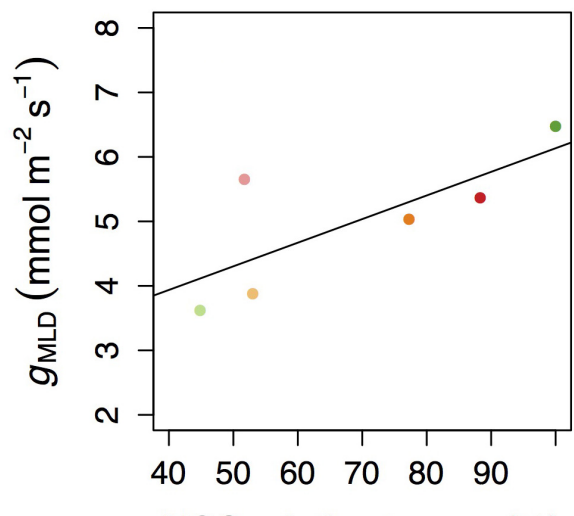

NSC relative to $\max (\%)$

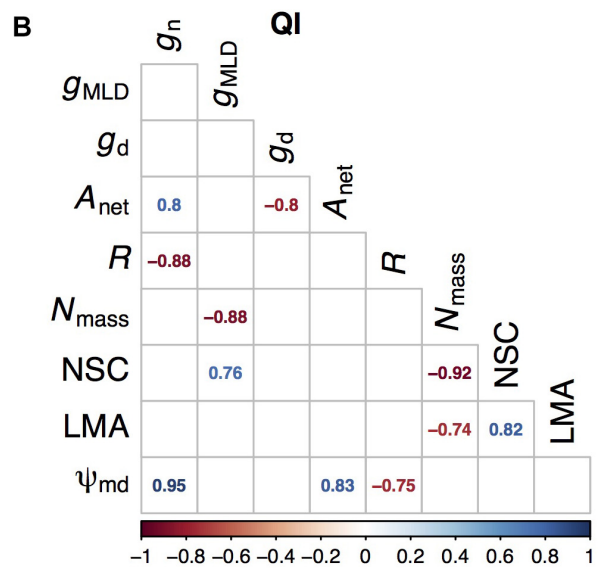

D

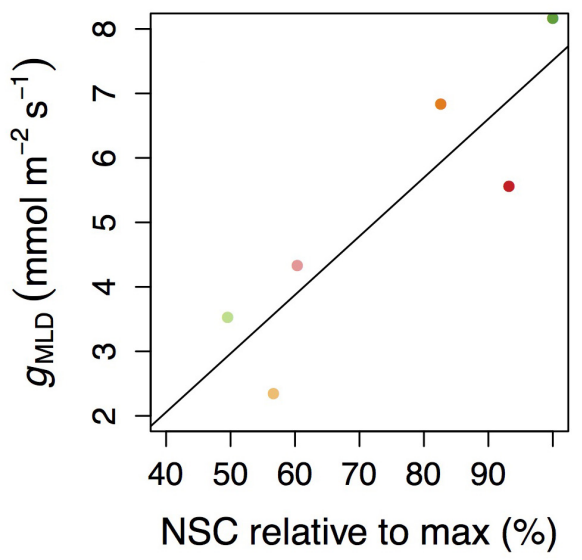

FIGURE 4 | Correlation table between the measured parameters in Q. faginea (Qf, A) and Q. ilex (Qi, B). Relationship between conductance measured as mass loss of detached leaves under and non-structural concentrations (NSC) in Qf (C) and Qi (D). NSC are provided relative to the maximum values measured in our experiment. Values in (C,D) indicate mean per treatment, and each treatment is indicated by a different color following the same convention as in Figures 1-3.

TABLE 2 | Model comparison. We compared for Q. faginea (QF) and Q. ilex (QI) different models based on the Akaike Information Criterion (AIC), the change in AIC relative to the lowest ( $\triangle \mathrm{AIC}$ ) and the $R^{2}$, slope and intercept of the observed vs predicted relationship. For the slope and intercept we show the mean value (and SE).

\begin{tabular}{|c|c|c|c|c|c|c|c|c|}
\hline \multirow{2}{*}{$Q F$} & \multirow[t]{2}{*}{ 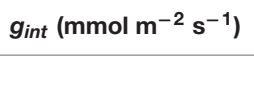 } & \multirow[t]{2}{*}{ AIC } & \multirow[t]{2}{*}{$\Delta \mathrm{AIC}$} & \multirow[t]{2}{*}{$R^{2}$} & \multicolumn{2}{|c|}{ Slope } & \multicolumn{2}{|c|}{ Intercept } \\
\hline & & & & & & & & \\
\hline $\mathrm{BBD}_{M L D}$ & 5.5 & -106.88 & 0 & 0.88 & 1.04 & $(0.09)$ & 0.001 & (0.005) \\
\hline $\mathrm{BBD}_{n}$ & 7.1 & -106.6 & 0.28 & 0.87 & 1.06 & $(0.09)$ & 0.0006 & $(0.005)$ \\
\hline $\mathrm{BBD}_{d}$ & 20.3 & -102.32 & 4.56 & 0.84 & 1.23 & $(0.13)$ & -0.013 & (0.007) \\
\hline $\mathrm{BB}^{1}$ & 8.9 & -102.3 & 4.58 & 0.85 & 1.02 & $(0.09)$ & -0.01 & (0.006) \\
\hline BB_meas_g $g_{M L D}$ & 5.5 & -104.3 & 2.58 & 0.86 & 0.99 & $(0.09)$ & 0.002 & $(0.005)$ \\
\hline \multicolumn{9}{|l|}{ QI } \\
\hline $\mathrm{BBD}_{M L D}$ & 5.3 & -98.52 & 1.64 & 0.97 & 1.2 & $(0.05)$ & -0.0001 & (0.003) \\
\hline $\mathrm{BBD}_{n}$ & 9.1 & -96.22 & 3.94 & 0.97 & 1.2 & $(0.05)$ & -0.002 & (0.008) \\
\hline $\mathrm{BBD}_{d}$ & 58.2 & -69.92 & 30.24 & 0.85 & 1.6 & $(0.17)$ & -0.067 & $(0.01)$ \\
\hline $\mathrm{BB}^{1}$ & 16.8 & -98.14 & 2.02 & 0.98 & 1.3 & $(0.05)$ & -0.018 & $(0.004)$ \\
\hline BB_meas_gMLD & 5.3 & -100.16 & 0 & 0.98 & 1.2 & $(0.04)$ & -0.001 & (0.003) \\
\hline
\end{tabular}

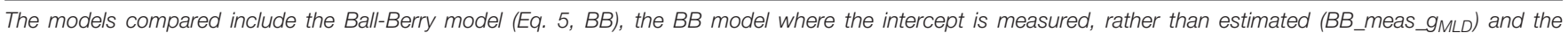

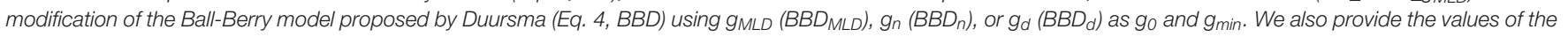

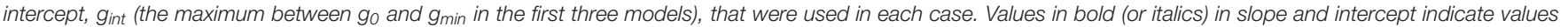
significantly (or marginally) different from 1 and 0 , respectively.

${ }^{1}$ Note that $g_{\text {int }}$ in this case is estimated through least squares, rather than measured as in the other models. 

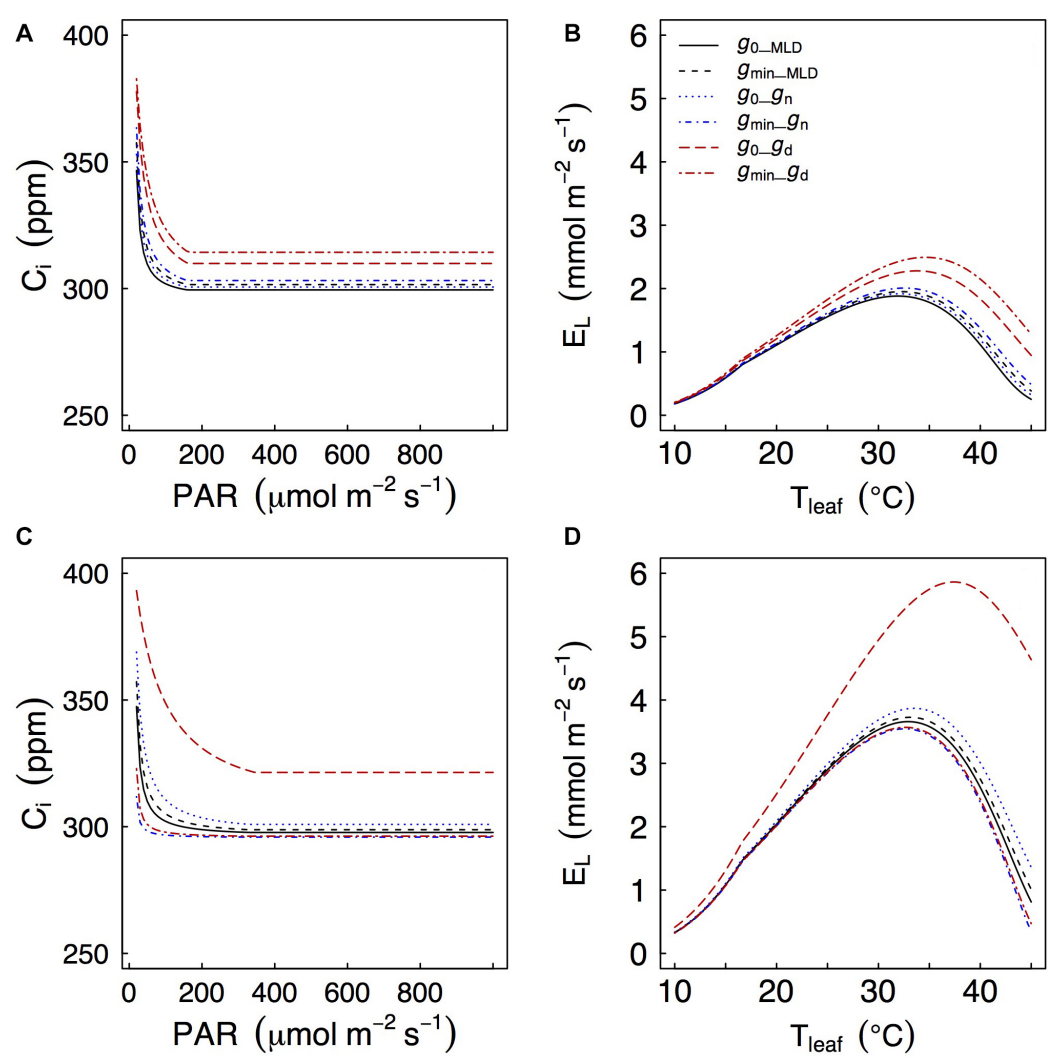

FIGURE 5 | Effects of different values of $g_{\text {res }}$ on a coupled photosynthesis model as in Duursma et al. (2019). Models are for Q. faginea (A,B) and Q. ilex (C,D). go

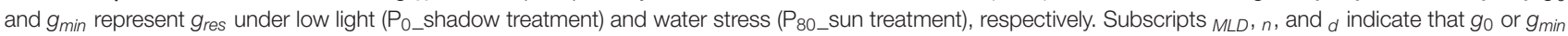
(depending on case) were estimated from mass loss of detached leaves, from nocturnal conductance, or from daytime conductance.

Q. faginea, whereas the increase in Q. ilex $g_{M L D}$ under sun was not significant.

\section{$g_{M L D}$ Correlated With Low NSC Concentrations}

We can speculate that the reason why $g_{M L D}$ was not lower under the high water stress and shade treatment (relative to other shade treatments under less water stress) is related to carbohydrate limitations. We observed a significant and positive correlation between NSC and $g_{M L D}$ across species. A synthesis of variation in NSC across species reports that a minimum NSC of $46 \%$ is always conserved (Martínez-Vilalta et al., 2016). In our results we also observed a minimum NSC that was close to the $46 \%$ of the maximum NSC that we measured (Figures 4C,D).

A possible explanation on why $g_{M L D}$ did not decrease further under the joint drought and shade stress is related to a lack of NSC to feed the building of additional wax and/or epidermal layers. That is, once plants have reached the minimum NSC threshold of $46 \%$ relative to maximum, they will seek to preserve their NSC for other functions, such as osmoregulation, at the expense of building thicker cuticles or additional wax layers. We note that osmoregulation under shade may be impaired in oaks (Aranda et al., 2005; Rodriguez-Calcerrada et al., 2010).

At any rate, this is the first study, to our knowledge to raise this possibility. This result should thus be interpreted with caution. We acknowledge that the correlation between $g_{M L D}$ and NSC may have been affected by jointly considering plants under different light and water regimes. Subsequent work would thus be needed to confirm this hypothesis.

\section{Residual Conductance in Relation to Respiration, LMA and $\boldsymbol{N}_{\text {mass }}$}

Despite stomatal closure, $g_{\text {res }}$ did not limit $\mathrm{CO}_{2}$ diffusion out of the leaf. In fact, there was a negative correlation between nocturnal conductance and respiration in one of our (Q. ilex) species, indicating higher $\mathrm{CO}_{2}$ efflux at lower $g_{n}$ and, consequently, that reduced $g_{n}$ levels were far from limiting respiration. This contradicts earlier studies that cytotoxic $\mathrm{CO}_{2}$ build-up could occur under nocturnal stomatal closure (Fricke, 2019) but it aligns along with the results of modeling, indicating that only under conductances that are orders of magnitude lower to those reported here could a cytotoxic $\mathrm{CO}_{2}$ build-up occur (Resco De Dios et al., 2019).

$g_{M L D}$ increased in the sun in Q. faginea. LMA also increased with light (data not shown) and it was significantly correlated with $g_{n}$ and with $g_{M L D}$ in Q. faginea. LMA is an indicator of the degree of sclerophylly, which could serve to decrease residual conductance by increasing cuticle thickness. However, LMA also increased with light in the sclerophyll $Q$. ilex, where LMA did not correlate with $g_{n}$ or $g_{M L D}$. This result matches with previous 
studies in Quercus indicating that any effects of LMA in $g_{n}$ and $g_{M L D}$ may be modified by changes in the cuticle composition (Bueno et al., 2020). We note that this argument is speculative and based only on circumstantial evidence.

$N_{\text {mass }}$ showed a negative correlation with $g_{M L D}$ in both species, and with $g_{n}$ in $Q$. faginea. This result indicates that species with a higher photosynthetic investment will decrease the investment in residual conductance. This points toward a potential mechanism underlying the trade-off between investment for C uptake (higher $N_{\text {mass }}$ ) and preventing catastrophic water losses (reduced $g_{M L D}$ ). Further studies will be necessary to test the generality of this hypothesis.

\section{Residual Conductance May Be Measured via $g_{M L D}$ or via $g_{n}$ Under High $D$}

Measurements of nocturnal conductance under the relatively high $D$ from this experiment were statistically indistinguishable from independent measurements of residual conductance indicating that the latter was driving the former. It had been previously argued that measurements of $g_{n}$ would not be valid indicators of residual conductance, because $g_{n}$ is actively regulated (Duursma et al., 2019). Our results suggest that this argument from Duursma et al. (2019) may only be valid when $g_{n}$ is measured under low $D$.

Previous studies document that stomata often reach complete closure (or as complete as it can be) under lower $D$ in the night, than in the day (Barbour and Buckley, 2007). This phenomenon would explain why $g_{n}$ was much lower than $g_{d}$ although $D$ was comparable, and it is likely explained by the capacity of stomata to sense and open in response to light.

We also show how modeling results were not affected by either using $g_{M L D}$ or $g_{n}$. This result, however, needs to be interpreted with caution. We only focused on BB-type stomatal models and other results may be obtained in different model types. For instance, as Duursma et al. (2019) noted, changing minimum conductance from 2 to $4 \mathrm{mmol} \mathrm{m} \mathrm{m}^{-2} \mathrm{~s}^{-1}$ halved the time to reach mortality in a hydraulics model because it doubled the water losses (Duursma et al., 2019). Although differences were statistically not significant between $g_{M L D}$ and $g_{n}$, we still observed differences in mean residual conductance of $4 \mathrm{mmol} \mathrm{m}^{-2} \mathrm{~s}^{-1}$ across measurements, indicating that measurement errors and other sources of uncertainty may play a large for other model types, such as mortality models.

\section{Modeling $g_{s}$}

We acknowledge our dataset was limited to thoroughly test the best form of the BB model: we sampled under highly contrasting light and water conditions, but only once in time. We would thus need data over more time periods for a more thorough evaluation. However, our dataset allows for the development of some hypotheses, which may be expanded in subsequent studies.

We observed that there were only little differences between Eq. 5, where the original $\mathrm{BB}$ function was used but including measured $g_{M L D}$ (BB_meas_g $g_{M L D}$ ), instead of the version proposed by Duursma et al. (2019; Eq. 4). Duursma et al. (2019) note that residual conductance acts as an actual minimum in the function they propose. However, if the goal is to use residual conductance as an actual stomatal minimum, one could consider the following equation instead:

$$
g_{\mathrm{s}}=\max \left(\min \left(\mathrm{g}_{0}, \mathrm{~g}_{\min }\right), m \mathrm{ARH} / \mathrm{Ca}\right)
$$

where the minimum between $g_{0}$ and $g_{\min }$ is chosen [not the maximum, as proposed by Duursma et al. (2019)].

At any rate, we did not observe major differences in model performance between the BBD model or Eq. 5. This result indicates that it is unlikely that losses in model performance will derive from the adoption of the alternative model formulations, as proposed by previous studies (De Kauwe et al., 2015; Duursma et al., 2019).

Our results also indicate that $g_{M L D}$ and $g_{n}$ can both be interchangeably, and that the choice between $g_{0}$ and $g_{\text {min }}$ exerts negligible consequences for model fitting. Earlier studies indicate a major effect of $g_{\text {res }}$ (De Kauwe et al., 2015; Duursma et al., 2019). This is because those studies used a wide range of $g_{\text {res }}$ values (10-40 mmol m $\mathrm{m}^{-2} \mathrm{~s}^{-1}$, depending on the case), much higher that the variability we reported here when using $g_{M L D}$ and $g_{n}$ across treatments (Table 2). Synthesis studies similarly indicate limited variation in $g_{\text {res }}$ within a family (Duursma et al., 2019). After discarding $g_{d}$ as a reliable indicator of $g_{\text {res }}$, our results indicate a minor effect of different methods and approaches used for measuring $g_{\text {res }}$ and for modeling water use, at least in our two closely related species.

\section{DATA AVAILABILITY STATEMENT}

The raw data supporting the conclusions of this article will be made available by the authors, without undue reservation.

\section{AUTHOR CONTRIBUTIONS}

VR designed the experiment. CA performed research with the help of FC. VR analyzed the data and wrote the manuscript with important feedback from all co-authors. All authors contributed to the article and approved the submitted version.

\section{FUNDING}

We acknowledge funding from the Natural Science Foundation in China (31850410483), the talent proposals from Sichuan Province (2020JDRC0065), the Southwest University of Science and Technology talents fund (18ZX7131), and the Spanish MICINN (AGL2015-69151-R). EG is supported by MCIU/AEI/FEDER, UE [Postdoctoral Contract (IJCI-2017-32511)].

\section{ACKNOWLEDGMENTS}

We acknowledge technical assistance from P. Sopeña, M.J. Pau, B. Lavaquiol, A. Cunill, and J. Hedo. We remain grateful to 
earlier comments from E. Gil-Pelegrín, J.J. Peguero-Pina, D. Sancho-Knapik, D.G. Williams, and D.T. Tissue.

\section{SUPPLEMENTARY MATERIAL}

The Supplementary Material for this article can be found online at: https://www.frontiersin.org/articles/10.3389/fpls.2020. 603581/full\#supplementary-material

\section{REFERENCES}

Aranda, I., Bergasa, L. F., Gil, L., and Pardos, J. A. (2001). Effects of relative irradiance on the leaf structure of Fagus sylvatica L. seedlings planted in the understory of a Pinus sylvestris L. stand after thinning. Ann. For. Sci. 58, 673-680. doi: 10.1051/forest:2001154

Aranda, I., Castro, L., Pardos, M., Gil, L., and Pardos, J. A. (2005). Effects of the interaction between drought and shade on water relations, gas exchange and morphological traits in cork oak (Quercus suber L.) seedlings. For. Ecol. Manag. 210, 117-129. doi: 10.1016/j.foreco.2005.02.012

Ball, T. J., Woodrow, I. E., and Berry, J. A. (1987). “A model predicting stomatal conductance and its contribution to the control of photosynthesis under different environmental conditions," in Progress in Photosynthesis Research, ed. J. Biggins (Dordrecht: Martinus Nijhoff), 221-224. doi: 10.1007/978-94-0170519-6_48

Barbour, M. M., and Buckley, T. N. (2007). The stomatal response to evaporative demand persists at night in Ricinus communis plants with high nocturnal conductance. Plant Cell Environ. 30, 711-721. doi: 10.1111/j.1365-3040.2007. 01658.x

Barnard, D. M., and Bauerle, W. L. (2013). The implications of minimum stomatal conductance on modeling water flux in forest canopies. J. Geophys. Res. Biogeosci. 118, 1322-1333. doi: 10.1002/jgrg.20112

Blackman, C. J., Pfautsch, S., Choat, B., Delzon, S., Gleason, S. M., and Duursma, R. A. (2016). Toward an index of desiccation time to tree mortality under drought. Plant Cell Environ. 39, 2342-2345. doi: 10.1111/pce. 12758

Boyer, J. S., Wong, S. C., and Farquhar, C. D. (1997). CO $_{2}$ and water vapor exchange across leaf cuticle (epidermis) at various water potentials. Plant Physiol. 114, 185-191. doi: 10.1104/pp.114.1.185

Bueno, A., Sancho-Knapik, D., Gil-Pelegrin, E., Leide, J., Peguero-Pina, J. J., Burghardt, M., et al. (2020). Cuticular wax coverage and its transpiration barrier properties in Quercus coccifera L. leaves: does the environment matter?. Tree Physiol. 40, 827-840. doi: 10.1093/treephys/tpz110

Burnham, K. P., and Anderson, D. R. (2002). Model Selection and Multi/Model Inference: A Practical Information-Theoretic Approach. New York, NY: Springer-Verlag.

Collatz, G. J., Ball, J. T., Grivet, C., and Berry, J. A. (1991). Physiological and environmental regulation of stomatal conductance, photosynthesis and transpiration: a model that includes a laminar boundary layer. Agric. For. Meteorol. 54, 107-136. doi: 10.1016/0168-1923(91)90002-8

De Kauwe, M. G., Kala, J., Lin, Y. S., Pitman, A. J., Medlyn, B. E., Duursma, R. A., et al. (2015). A test of an optimal stomatal conductance scheme within the CABLE Land Surface Model. Geosci. Model. Dev. 8, 431-452. doi: 10.5194/ gmd-8-431-2015

Duarte, A. G., Katata, G., Hoshika, Y., Hossain, M., Kreuzwieser, J., Arneth, A., et al. (2016). Immediate and potential long-term effects of consecutive heat waves on the photosynthetic performance and water balance in Douglas-fir. J. Plant Physiol. 205, 57-66. doi: 10.1016/j.jplph.2016.08.012

Duursma, R. A. (2015). Plantecophys - an R package for analysing and modelling leaf gas exchange data. PLoS One 10:e0143346. doi: 10.1371/journal.pone. 0143346

Duursma, R. A., Blackman, C. J., Lopez, R., Martin-Stpaul, N. K., Cochard, H., and Medlyn, B. E. (2019). On the minimum leaf conductance: its role in models of plant water use, and ecological and environmental controls. New Phytol. 221, 693-705. doi: 10.1111/nph.15395
Supplementary Figure 1A | Variation in leaf non-structural carbohydrate concentrations measured across different light treatments (shadow vs sun) and water treatments $\left(P_{0}, P_{50}\right.$, and $\left.P_{80}\right)$ in Quercus faginea (QF) and $Q$. ilex (QI). Bars indicate mean values per treatment and error bars indicate SE.

Supplementary Table 1A | Target midday water potential $\left(\Psi_{m d}\right)$ to reach the desired PLC according to Esteso-Martínez et al. (2006) for Q. faginea and to Peguero-Pina et al. (2014) for Q. ilex, and actual values. Mean (and SE) actual values are presented. The letters in "Actual PLC" indicate the results of post hoc analyses (Tukey HSD). This is a reproduction (with permission from the publisher) of Table 1 originally published in Resco De Dios et al. (2020).

Esteso-Martínez, J., Camarero, J. J., and Gil-Pelegrín, E. (2006). Competitive effects of herbs on Quercus faginea seedlings inferred from vulnerability curves and spatial-pattern analyses in a Mediterranean stand (Iberian System, northeast Spain). Écoscience 13, 378-387. doi: 10.2980/i1195-6860-13-3-378.1

Fernández, V., Bahamonde, H. A., Javier Peguero-Pina, J., Gil-Pelegrín, E., SanchoKnapik, D., Gil, L., et al. (2017). Physico-chemical properties of plant cuticles and their functional and ecological significance. J. Exp. Bot. 68, 5293-5306. doi: 10.1093/jxb/erx302

Flexas, J., Barbour, M. M., Brendel, O., Cabrera, H. M., Carriqui, M., Diaz-Espejo, A., et al. (2012). Mesophyll diffusion conductance to $\mathrm{CO}_{2}$ : an unappreciated central player in photosynthesis. Plant Sci. 193-194, 70-84. doi: 10.1016/j. plantsci.2012.05.009

Fricke, W. (2019). Night-time transpiration - favouring growth? Trends Plant Sci. 24, 311-317. doi: 10.1016/j.tplants.2019.01.007

Heredia-Guerrero, J. A., Guzman-Puyol, S., Benitez, J. J., Athanassiou, A., Heredia, A., and Dominguez, E. (2018). Plant cuticle under global change: biophysical implications. Glob. Chan. Biol. 24, 2749-2751. doi: 10.1111/gcb. 14276

Hetherington, A. M., and Woodward, F. I. (2003). The role of stomata in sensing and driving environmental change. Nature 424, 901-908. doi: 10.1038/ nature 01843

Hoffman, A. S., Albeke, S. E., Mcmurray, J. A., Evans, R. D., and Williams, D. G. (2019). Nitrogen deposition sources and patterns in the greater yellowstone ecosystem determined from ion exchange resin collectors, lichens, and isotopes. Sci. Total Environ. 683, 709-718. doi: 10.1016/j.scitotenv.2019.05.323

Kerstiens, G. (1996). Cuticular water permeability and its physiological significance. J. Exp. Bot. 47, 1813-1832. doi: 10.1093/jxb/47.12.1813

Leuning, R. (1995). A critical appraisal of a combined stomatal-photosynthesis model for C3 plants. Plant Cell Environ. 18, 339-355. doi: 10.1111/j.1365-3040. 1995.tb00370.x

Lombardozzi, D. L., Zeppel, M. J. B., Fisher, R. A., and Tawfik, A. (2017). Representing nighttime and minimum conductance in CLM4.5: global hydrology and carbon sensitivity analysis using observational constraints. Geosci. Model. Dev. 10, 321-331. doi: 10.5194/gmd-10-321-2017

Long, S. P., and Bernacchi, C. J. (2003). Gas exchange measurements, what can they tell us about the underlying limitations to photosynthesis? Procedures and sources of error. J. Exp. Bot. 54, 2393-2401. doi: 10.1093/jxb/erg262

Martínez-Vilalta, J., Sala, A., Asensio, D., Galiano, L., Hoch, G., Palacio, S., et al. (2016). Dynamics of non-structural carbohydrates in terrestrial plants: a global synthesis. Ecol. Monogr. 86, 495-516. doi: 10.1002/ecm.1231

Martin-Stpaul, N., Delzon, S., and Cochard, H. (2017). Plant resistance to drought depends on timely stomatal closure. Ecol. Lett. 20, 1437-1447. doi: 10.1111/ele. 12851

Ogle, K., Lucas, R. W., Bentley, L. P., Cable, J. M., Barron-Gafford, G. A., Griffith, A., et al. (2012). Differential daytime and night-time stomatal behavior in plants from North American deserts. New Phytol. 194, 464-476. doi: 10.1111/j.14698137.2012.04068.x

Palacio, S., Maestro, M., and Montserrat-Marti, G. (2007). Relationship between shoot-rooting and root-sprouting abilities and the carbohydrate and nitrogen reserves of Mediterranean dwarf shrubs. Ann. Botany 100, 865-874. doi: 10. 1093/aob/mcm 185

Peguero-Pina, J. J., Sancho-Knapik, D., Barron, E., Camarero, J. J., Vilagrosa, A., and Gil-Pelegrin, E. (2014). Morphological and physiological divergences within Quercus ilex support the existence of different ecotypes depending on climatic dryness. Ann. Bot. 114, 301-313. doi: 10.1093/aob/mcu108 
Phillips, N. G., Lewis, J. D., Logan, B. A., and Tissue, D. T. (2010). Inter- and intraspecific variation in nocturnal water transport in Eucalyptus. Tree Physiol. 30, 586-596. doi: 10.1093/treephys/tpq009

R Core Team (2020). R: A Language and Environment for Statistical Computing. Vienna: R Foundation for Statistical Computing.

Resco, V., Ewers, B. E., Sun, W., Huxman, T. E., Weltzin, J. F., and Williams, D. G. (2009). Drought-induced hydraulic limitations constrain leaf gas exchange recovery after precipitation pulses in the C3 woody legume, Prosopis velutina. New Phytol. 181, 672-682. doi: 10.1111/j.1469-8137.2008.02687.x

Resco De Dios, V., Arteaga, C., Peguero-Pina, J. J., Sancho-Knapik, D., Qin, H., Zveushe, O. K., et al. (2020). Hydraulic and photosynthetic limitations prevail over root non-structural carbohydrate reserves as drivers of resprouting in two Mediterranean oaks. Plant Cell Environ. 43, 1944-1957. doi: 10.1111/pce.13781

Resco De Dios, V., Chowdhury, F. I., Granda, E., Yao, Y., and Tissue, D. T. (2019). Assessing the potential functions of nocturnal stomatal conductance in C3 and C4 plants. New Phytol. 223, 1696-1706. doi: 10.1111/nph.15881

Resco De Dios, V., Diaz-Sierra, R., Goulden, M. L., Barton, C. V., Boer, M. M., Gessler, A., et al. (2013). Woody clockworks: circadian regulation of night-time water use in Eucalyptus globulus. New Phytol. 200, 743-752. doi: 10.1111/nph. 12382

Resco De Dios, V., Roy, J., Ferrio, J. P., Alday, J. G., Landais, D., Milcu, A., et al. (2015). Processes driving nocturnal transpiration and implications for estimating land evapotranspiration. Sci. Rep. 5:10975.

Riederer, M., and Müller, C. (2007). Biology of the Plant Cuticle. Hoboken, NJ: Blackwell Publishing.

Rodriguez-Calcerrada, J., Pardos, J. A., and Aranda, I. (2010). Contrasting responses facing peak drought in seedlings of two co-occurring oak species. Forestry 83, 369-378. doi: 10.1093/forestry/cpq019
Schuster, A. C., Burghardt, M., and Riederer, M. (2017). The ecophysiology of leaf cuticular transpiration: are cuticular water permeabilities adapted to ecological conditions? J. Exp. Bot. 68, 5271-5279. doi: 10.1093/jxb/ erx321

Shepherd, T., and Wynne Griffiths, D. (2006). The effects of stress on plant cuticular waxes. New Phytol. 171, 469-499.

Way, D. A., and Pearcy, R. W. (2012). Sunflecks in trees and forests: from photosynthetic physiology to global change biology. Tree Physiol. 32, 10661081.

Wei, T., and Simko, V. (2017). R Package "Corrplot": Visualization of a Correlation Matrix (Version 0.84). Available online at: https://github.com/taiyun/corrplot (accessed September 1, 2020).

Zhang, P., Wen, Y., Wang, L., Zhang, H., Wang, G. G., and Wu, T. (2020). Leaf structural carbohydrate decreased for Pinus thunbergii along coast-inland gradients. Forests 11:449.

Conflict of Interest: The authors declare that the research was conducted in the absence of any commercial or financial relationships that could be construed as a potential conflict of interest.

Copyright (C) 2020 Qin, Arteaga, Chowdhury, Granda, Yao, Han and Resco de Dios. This is an open-access article distributed under the terms of the Creative Commons Attribution License (CC BY). The use, distribution or reproduction in other forums is permitted, provided the original author(s) and the copyright owner(s) are credited and that the original publication in this journal is cited, in accordance with accepted academic practice. No use, distribution or reproduction is permitted which does not comply with these terms. 